\title{
A Novel Fault Analysis Method of the Power Grid with Different Types of Wind Turbines
}

\author{
Chen Peng ${ }^{1, a}$, Zhang Zhe ${ }^{1}$,Yin Xianggen ${ }^{1}$,Yang Zengli ${ }^{2}$, Wang Lijun ${ }^{2}$ \\ ${ }^{1}$ State Key Laboratory of Advanced Electromagnetic Engineering and Technology (Huazhong \\ University of Science and Technology), Wuhan, China \\ ${ }^{2}$ State Grid Hubei Electric Power Company, Wuhan, China \\ awd_chenpeng@foxmail.com
}

\begin{abstract}
Keywords: wind turbines; direct-driven wind turbine generator; doubly-fed induction generator; fault current calculation method

Abstract. In order to solve the problem that different types of wind turbines accessing to the power gird has great influence on protection configuration and setting calculation, a fault current calculation model of doubly-fed induction generator under rotor excitation control was established when symmetric or asymmetric fault occurs in grid. Combined with fault current calculation models of direct-driven wind turbine generator and doubly-fed induction generator with crowbar protection, this paper establishes fault current calculation models of direct-driven wind turbine generator and doubly-fed induction generator, respectively. It is based on iterative solution by nodal voltage equation, fault boundary conditions and fault current calculation models of distributed generators. At last, the accuracy of the fault analysis method is verified by digital simulation.
\end{abstract}

\section{Introduction}

Fault current calculation of the power grid is the important foundation of relay protection performance study, especially the protection setting calculation. With the capacity of wind turbines connected to the power grid increasing, it has a great influence on power grid's safety and stable operation. Especially, compared with the fault current characteristics of traditional synchronous generator, it is different that the fault current characteristics of wind turbines. The traditional fault analysis method of the power grid is difficult to meet the requirements of fault analysis of the power grid with wind turbines [1,2]. So far, there is no applicable fault analysis method to calculate the fault current of the power grid with different types of wind turbines, accurately. Therefore, the study of the related fault analysis method is an urgent problem to be solved.

Establishing the fault current calculation model of wind turbines is the premise of fault current calculation method of the power grid with different types of wind turbines. Therefore, a large amount of researches has been done on the fault current characteristics of wind turbines and its calculation method.

According to the size of the power electronic converter's capacity, the existing wind turbines can be divided into some power wind turbines and full power wind turbines, such as doubly-fed induction generator (DFIG) and direct-driven wind turbine generator (DWTG), respectively. DWTG's stator windings are all connected to the power grid through the grid-connected inverter, which can be called inverter interfaced distributed generator (IIDG)[3]. IIDG should provide dynamic reactive power to support grid voltage in low voltage ride through (LVRT) and the fault current characteristics of IIDG are studied in [4]. And the positive sequence voltage controlled current source model is established for IIDG considering control strategy in [5].

Unlike DWTG, DFIG always installs crowbar to improve the ability of LVRT. Crowbar's action situation has a great influence on the fault current. In [7,8], flux transient characteristics of DFIG with crowbar action are analyzed, and the authors deduce stator and rotor fault current expressions. Furthermore, for the current calculation model of DFIG under rotor excitation control, considering DFIG should provide dynamic reactive power to support grid voltage in LVRT, stator fault current 
expression of DFIG under rotor excitation control has been deduced under symmetric or asymmetric fault in [9-11].

However, fault current calculation methods above all only consider a kind of wind turbines accessing to the power grid, which doesn't comprehensively consider DWTG, DFIG with crowbar action and DFIG under rotor excitation control. The power plants with wind turbines always contain different typies of wind turbines. Hence, fault current calculation methods above all aren't comprehensive.

Considering operation characteristics of different types of wind turbines, this paper establishs a fault current calculation model of DFIG under rotor excitation control when symmetric or asymmetric fault occurs in grid. Then, combined with fault current calculation models of DWTG and DFIG with crowbar protection, a novel fault analysis method of power grid with different types of wind turbines is presented. In the end, the fault analysis method proposed was verified by digital simulation in PSCAD.

\section{Fault current calculation model of wind turbines}

Due to the different fault current characteristics of different types of wind turbines, it is particularly important to establish the fault current calculation model for DFIG and DWTG, respectively.

\section{(1) Fault current calculation model of DWTG}

During the grid fault, DWTG can be regarded as voltage controlled current source which only contains positive sequence current in [4,5]. The fault current $\oint_{D W T G}^{\alpha}=I_{D W T G} \angle \varphi_{i}$ is rated to DWTG's terminal positive sequence voltage $\&_{D W T G(1)}^{\&}=V_{D W T G(1)} \angle \varphi_{v}$. Considering DWTG should provide dynamic reactive power to support grid voltage in LVRT, DWTG uses d-axis orientation of the grid voltage vector control technology. The fault current equivalent mathematical model $\delta_{D W T G}=f_{D W T G}\left(I_{D W T G(1)}^{\mathcal{E}}\right)$ is shown as follows

(1) If $V_{D W T G(1)} \geq 0.9$, DWTG needn't provide reactive power, thus $I_{D W T G}=i_{d 0}^{*}, \varphi_{i v}=\varphi_{i}-\varphi_{v}=0$.

(2) If $V_{D W T G(1)}<0.9$, referenced reactive current is $i_{q}^{*}=-2\left(1-V_{D W T G(1)}\right)$. During the fault, To prevent the grid inverter over current, DWTG's limit current is $I_{D W T G . s e t}$.If $i_{q}^{*} \leq \sqrt{I_{D W T G . s e t}^{2}-\left(i_{d 0}^{*}\right)^{2}}$, thus $I_{I I D G}=\sqrt{\left(i_{d 0}^{*}\right)^{2}+4\left(1-V_{D W T G(1)}\right)^{2}}, \varphi_{i v}=\arctan \left(i_{q}^{*} / i_{d 0}^{*}\right)$; If $i_{q}^{*}>\sqrt{I_{D W T G . s e t}^{2}-\left(i_{d 0}^{*}\right)^{2}}$, thus $I_{D W T G}=I_{D W T G . s e t}$, $i_{q}^{*}=-2\left(1-V_{D W T G(1)}\right), i_{d}^{*}=\sqrt{I_{D W T G . s e t}^{2}-4\left(1-V_{D W T G(1)}\right)^{2}}, \quad \varphi_{i v}=\arctan \left(i_{q}^{*} / i_{d}^{*}\right)$.

Where $i_{d 0}^{*}$ represents the referenced active current in grid inverter current inner loop. $\varphi_{i v}$ represents the angle from the fault current to the DWTG terminal positive sequence voltage.

\section{(2) Fault current calculation model of DFIG}

During the grid fault, DFIG's crowbar action situation has a great influence on its fault current. Thus, according to crowbar action situation, fault current calculation model of DFIG is analyzed. For DFIG with crowbar action, the analytical expressions of stator and rotor fault current calculation model are deduced in [8]. And the fault current calculation model of DFIG with crowbar action can be regarded as an asynchronous induction motor. For DFIG under rotor excitation control, the fault current calculation model is established in [11]. The fault current of DFIG under rotor excitation control can be expressed as $\alpha_{D F I G(1)}^{\alpha}=I_{D F I G(1)} \angle \delta_{i(1)}$ and $\delta_{D F I G(2)}=I_{D F I G(2)} \angle \delta_{i(2)}, \delta_{D F I G(1)}, \hat{\alpha}_{D F I G(2)}$ represents the positive and negative sequence component of the fault current, respectively. They are all rated to DFIG's terminal positive sequence voltage $\sum_{D F I G(1)}=V_{D F I G(1)} \angle \delta_{v(1)}$ and negative sequence voltage $V_{D F I G(2)}^{\&}=V_{D F I G(2)} \angle \delta_{v(2)}$, where $V_{D F I G(1)}=u_{s d+}^{+}, V_{D F I G(2)}=u_{s d-}^{-}$. As this paper regards eliminating the negative sequence component of stator current as a control target in DFIG's control 
system, the fault current of DFIG under rotor excitation control only contains positive sequence current. Hence, the fault current $\oint_{D F I G(1)}=f_{D F I G(1)}\left(\sum_{D F I G(1)}^{\&}, V_{D F I G(2)}^{\&}\right)$ is expressed as

$$
\left\{\begin{array}{l}
I_{D F I G(1)}=\sqrt{\left(-i_{s d+}^{+}\right)^{2}+\left(-i_{s q^{+}}^{+}\right)^{2}} \\
\delta_{i(1)}=\arctan \left[\left(-i_{s q+}^{+}\right) /\left(-i_{s d+}^{+}\right)\right]+\delta_{v(1)}
\end{array}\right.
$$

And $i_{s d+}^{+} 、 i_{s q+}^{+} 、 i_{s d-}^{-} 、 i_{s q-}^{-}$is

$$
\left\{\begin{array}{l}
i_{s d+}^{+}=-\frac{L_{m}}{L_{s}} \min \left(\frac{P_{s 0} L_{s}}{u_{s d+}^{+} L_{m}}, \sqrt{I_{\text {rset }}^{2}-i_{r q+}^{+* 2}-i_{r q-}^{-*}}\right) \\
i_{s q+}^{+}=-2 \times\left(0.9-u_{s d+}^{+}\right) ; i_{s d-}^{-}=0 ; i_{s q-}^{-}=0
\end{array}\right.
$$

Where $i_{r q-}^{-*}=\frac{u_{s d-}^{-}}{\omega_{1} L_{m}}, i_{r q+}^{+*}=-\frac{u_{s d+}^{+}}{\omega_{1} L_{m}}-\frac{2 L_{s}}{L_{m}}\left(0.9-u_{s d+}^{+}\right) ; P_{s 0}$ represents stator active power before fault occurs, $I_{r \text { set }}$ represents DFIG's limit rotor current. $u_{s d+}^{+}, u_{s q+}^{+}, u_{r d+}^{+}, u_{r q+}^{+}, i_{s d+}^{+}, i_{s q+}^{+}, i_{r d+}^{+}$and $i_{r q+}^{+}$represent stator and rotor's voltage and current in positive dq-synchronous reference frames, respectively. $u_{s d_{-}-}^{-}$, $u_{s q_{-}}^{-}, u_{r d-}^{-}, u_{r q_{-}}^{-}, i_{s d_{-}^{-}}^{-}, i_{s q_{-}^{-}}^{-}, i_{r d-}^{-}$and $i_{r q_{-}^{-}}^{-}$represent stator and rotor's voltage and current in negative dq-synchronous reference frames, respectively. $R_{s}$ represents stator resistance. $R_{r}$ represents rotor resistance. $L_{s}, L_{m}$ represents stator self-inductance, stator and rotor mutual-inductance in dq-synchronous reference frames.

\section{Fault current calculation method for the power grid with different types of wind turbines}

Through establishing each sequence equivalent circuit, the traditional fault current calculation method of the power grid combines each sequence node voltage equations and fault boundary condition equations. During the grid fault, DWTG and DFIG under rotor excitation control have strong nonlinear characteristic. Then, the traditional fault current calculation method is out of commission. Thus, this paper uses iterative solution to calculate fault current.

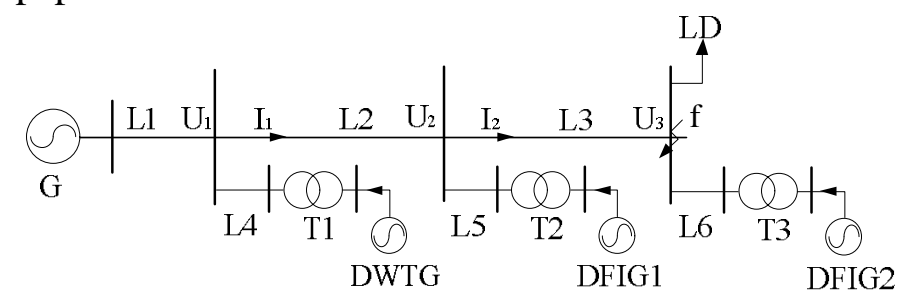

Fig.1. Structure diagram of power grid with wind turbines

In order to explain the fault current calculation method for the power grid with different types of wind turbines, a grid structure is established as shown in fig. 1 . Fault is set at $f$, it's a near fault for DFIG2, which runs with crowbar action during the fault. far fault occurs for DFIG1, whose rotor is under excitation control by rotor-side converter.

Based on this, this paper uses processing mode of fault current calculation method of the power grid with different types of wind turbines as follows. As DFIG with crowbar action are regarded as an asynchronous induction motor duiring the fault. the positive and negative sequence equivalent impedances of DFIG with crowbar action are respectively connected to the corresponding node in the positive and negative sequence network. And they are regarded as load branch in the network. DWTG and DFIG under rotor excitation control are regarded as voltage controlled current source in positive sequence network, and open circuit in negative sequence network. Other parts in the network are the same with traditional processing method.

Then, 3-phase fault and the 2-phase fault are regarded as examples to explain the calculation process of fault current calculation method. 
(1) Form the sequence network and node admittance matrix of composite sequence network

Firstly, form the node admittance matrix $Y_{(1)}$ of positive sequence network, and obtain the node impedance matrix $Z_{(1)}$ of positive sequence network.

Then, the diagram of composite sequence network is set up as shown in fig.2. The value of $Y_{\Delta}$ is based on the fault type at $f$.

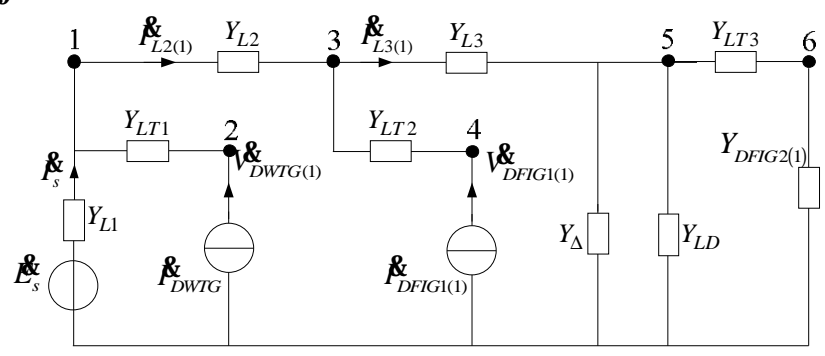

Fig.2 Diagram of composite sequence network

In Fig. 2, $Y_{L 1}, Y_{L 2}, Y_{L 3}$ are respectively branch admittance of L1、L2、L3; $Y_{L T 1}, Y_{L T 2}, Y_{L T 3}$ are respectively transformer branch admittance; $Y_{L D}$ is load branch admittance; $Y_{D F I G 2(1)}$ is positive sequence impedance of DFIG2; $v_{D W T G(1)}^{\&}, V_{D W T G 1(1)}^{\&}$ are respectively positive sequence voltage of DWTG and DFIG1.

(A) If 3-phase fault occurs at $f$, and $Z_{f}$ is grounding impedance, thus $Y_{\Delta}=1 / Z_{f}$.

(B) If 2-phase fault occurs at $\boldsymbol{f}$, there are negative sequence components of voltage and current in the network. The diagram of negative sequence network is established as shown in fig.3. Firstly, obtain the node admittance matrix $Y_{(2)}$ of negative sequence network. Then, obtain the node impedance matrix $Z_{(2)}$ of negative sequence network. The self-impedance is $Z_{(2)}(5,5)$ at $f$. According to the boundary condition of 2-phase fault $\delta_{f(1)}=\mathscr{l}_{f(2)}$, the positive sequence network and negative sequence network are parallel in fault point. Thus, $Y_{\Delta}=1 / Z_{(2)}(5,5)$.

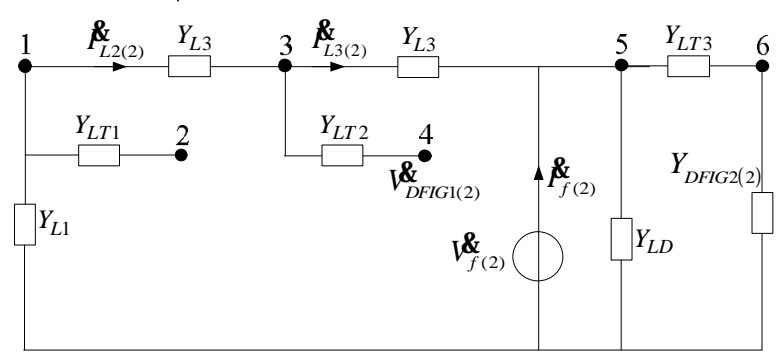

Fig.3 Diagram of negative sequence network

In Fig.3, $Y_{D F I G 2(2)}$ is negative sequence impedance of DFIG2, $V_{D F I G 1(2)}^{\&}$ is negative sequence voltage of DFIG1.

In the end, the node admittance matrix $Y_{m}$ of composite sequence network is formed, and the node impedance matrix $Z_{m}$ of the composite sequence network is obtained by $Y_{m}$.

(2) Form the iterative calculation equations

According to the equation of composite sequence network, iterative computation equations and iterative correction equations are formed as shown in equation (3), (4) (8). 


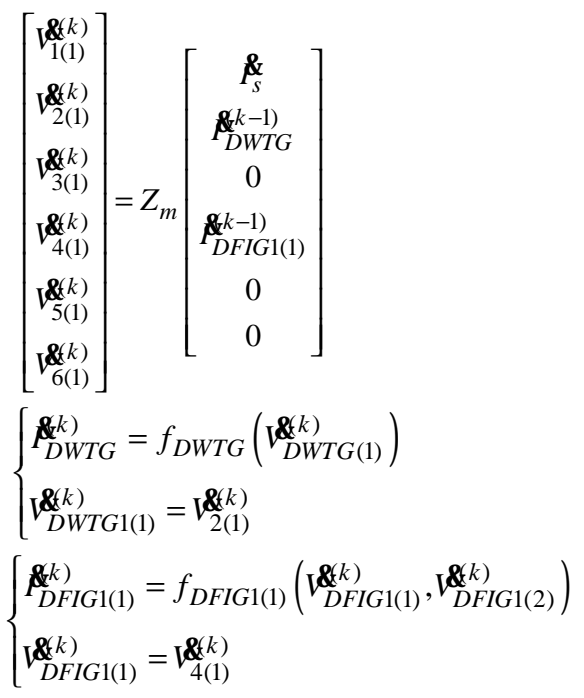

(A) If 3-phase fault occurs at $\boldsymbol{f}$, thus $V_{D F I G 1(2)}^{\&}=0$, the k-st iteration current is obtained in 3-phase fault by equation(4) and (5).

(B) If 2-phase fault occurs at $\boldsymbol{f}$, by equation(5), fault current of DFIG1 is related to the generator terminal negative sequence voltage ${ }_{D F I G 1(2)}^{\delta(k)}$, and ${ }_{D F I G 1(2)}^{\delta_{k}(k)}$ can only be solved in the negative sequence network. $v_{f(2)}^{\&(k)}=v_{f(1)}^{\delta(k)}=v_{5(1)}^{\& k)}$ as shown in fig.3.

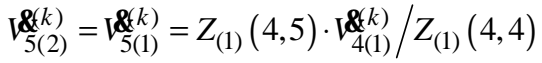

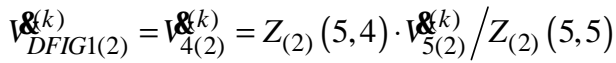

Thus, the iterative correction equation of DFIG1can be expressed as

$$
\delta_{D F I G 1(1)}^{(k)}=f_{D F I G 1(1)}^{\prime}\left(\&_{D F I G 1(1)}(k)\right)
$$

Therefore, form the k-st iteration current matrix $I^{(k) T}=\left[\begin{array}{llllll}\delta_{s}^{\alpha} & f_{D W T G}^{(k)} & 0 & f_{D F I G 1(1)}^{(k)} & 0 & 0\end{array}\right]$.

For iteration initial current matrix $I^{(0) T}$, iterative current of nodes accessing synchronous motor is its injection current, and remains constant. Iterative initial current of nodes accessing DWTG and

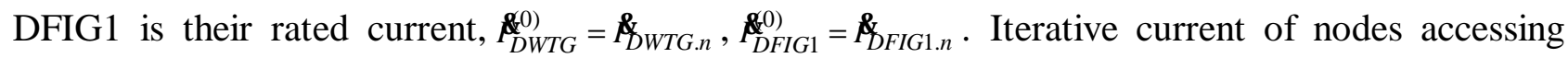
DFIG2 and other load branch is always 0.

\section{(3) Form the iterative convergence conditions}

Calculate the absolute value of difference between the k-st iteration node voltage $\&_{j}^{k)}$ and (k-1)-st iteration node voltage $\delta_{j}^{(k-1)}$. Determine it whether meet the iteration error threshold value

$$
\max \left|\delta_{j}^{(k)}-\varepsilon_{j}^{(k-1)}\right|<\varepsilon
$$

Where $j \in$ nodes accessed to wind turbines, $\varepsilon$ represents iteration error threshold value.

If it doesn't meet (9), the k-st iteration current matrix $I^{(k) T}=\left[\begin{array}{llllll}\alpha_{s}^{k} & F_{D W T G}^{(k)} & 0 & I_{D F I G 1}^{(k)} & 0 & 0\end{array}\right]$ will be substituted into the iterative calculation equation, sequentially.

If it meets (9), the iterative calculation is over, then obtain positive sequence voltage of each node

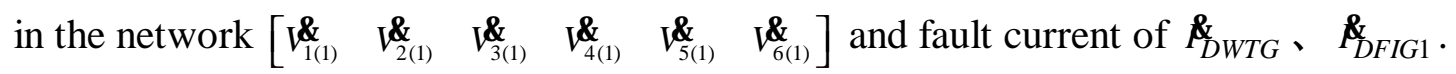

On this basis, according to the fault boundary condition, negative sequence voltage of fault node can be obtained. And obtain negative sequence voltage of each node in the negative network. In the end, the positive sequence current and negative sequence current of each branch in the network can be obtained. 


\section{Validation of the simulation}

In order to verify the correctness of the fault analysis method proposed in this paper. The model of the power grid with DWTG and DFIGs shown in fig.1 is established in PSCAD/EMTDC. Where, the transmission lines are all the same, unit length line parameter is $r_{(1)}=r_{(2)}=0.17 \Omega / \mathrm{km}$, $x_{(1)}=x_{(2)}=0.394 \Omega / \mathrm{km}, r_{(0)}=0.19 \Omega / \mathrm{km}, x_{(0)}=0.43 \Omega / \mathrm{km}$, the length of the line $L_{1} 、 L_{2} 、 L_{3}$ are $1 \mathrm{~km}, 2 \mathrm{~km}, 4 \mathrm{~km}$, respectively. $L_{1} 、 L_{2} 、 L_{3}$ are all $0.2 \mathrm{~km}$. The capacity of DFIGs is $1.5 \mathrm{MW}$, Rated line voltage is $690 \mathrm{~V}$, Stator leakage resistance is 0.1245 p.u. Rotor leakage resistance is 0.1245 p.u. Stator mutual inductance is 2.1767 p.u. Rotor speed is 0.8 p.u. The rotor limit current $I_{r s e t}$ of DFIG is 1.2 p.u. The capacity of DWTG is $1.5 \mathrm{MW}$, rated line voltage is $690 \mathrm{~V}$. The limit current $I_{D W T G . s e t}$ of DWTG is 1.2 p.u. In addition, the capacity of 3 double-winding transformers is $2 / 2 \mathrm{MVA}$, ratio is $0.69 / 36.75 \mathrm{kV}$, link category is $\mathrm{Yd}$, leakage reactance is $6.5 \%$. The equivalent impedance of LD is $120+\mathrm{j} 39.1 \Omega$.

In the established simulation platform, fault is set at $f$, and simulate the network as shown in Fig.1, when symmetric or asymmetric fault occurs at $f$. At the same time, according to the process of the software developed in this paper, calculate the fault current of the power grid with wind turbines as shown in Fig.1. Then, 3-phase fault and BC-phase fault are regarded as examples to analyze the fault current by comparing with the output results of fault current calculation software and simulation results.

On condition that 3-phase and BC-phase fault occurs at $f$, wind turbines are fully loaded before fault occurs. Compared with the output results of the software of fault current calculation and simulation results, fault current of wind turbines and main branchs is shown in Table 1 and Table2, respectively.

Table 1 Branch and wind turbines' fault currents on condition that 3-phase fault occurs at $\boldsymbol{f}$

\begin{tabular}{|c|c|c|c|c|c|c|}
\hline & $\mathbf{I}_{\text {DWTG }} / \mathbf{A}$ & $\mathbf{I}_{\text {DFIG1 }} / \mathbf{A}$ & $\mathbf{I}_{\text {DFIG } 2} / \mathbf{A}$ & $\mathbf{I}_{1} / \mathbf{k A}$ & $\mathbf{I}_{2} / \mathbf{k A}$ & Fault current $($ Ifa $/ \mathbf{k A})$ \\
\hline $\begin{array}{c}\text { Simulated } \\
\text { value }\end{array}$ & $23.71<-0.13^{\circ}$ & $23.71<-24.52^{\circ}$ & $0.00<-$ & $7.05 \angle-66.72^{\circ}$ & $7.07<-66.53^{\circ}$ & $7.07<-66.61^{\circ}$ \\
\hline $\begin{array}{c}\text { Calculated } \\
\text { value }\end{array}$ & $23.17 \angle-1.45^{\circ}$ & $23.25 \angle-23.87^{\circ}$ & $0.00 \angle-$ & $7.04 \angle-66.36^{\circ}$ & $7.05 \angle-66.22^{\circ}$ & $7.05 \angle-66.22^{\circ}$ \\
\hline
\end{tabular}

Table 2 Branch and wind turbines' fault currents on condition that BC-phase fault occurs at $f$

\begin{tabular}{|c|c|c|c|c|c|c|}
\hline & \multicolumn{2}{|c|}{ I DWTG /A } & \multicolumn{2}{|c|}{ I DFIG1/A } & \multicolumn{2}{|c|}{ I DFIG2 /A } \\
\hline & Pos.-Seq. comp. & Neg.-Seq. comp. & Pos.-Seq. comp. & Neg.-Seq. comp. & Pos.-Seq. comp. & Neg.-Seq. comp. \\
\hline $\begin{array}{l}\text { Simulated } \\
\text { value }\end{array}$ & $23.53<3.12^{\circ}$ & $0.00<-$ & $24.21<-6.13^{\circ}$ & $0.00<-$ & $10.84 \angle 138.43^{\circ}$ & $32.95<109.45^{\circ}$ \\
\hline \multirow[t]{3}{*}{$\begin{array}{c}\text { Calculated } \\
\text { value }\end{array}$} & $22.56<1.76^{\circ}$ & $0.00<-$ & $23.54<-5.29^{\circ}$ & $0.00<-$ & $10.71<137.11^{\circ}$ & $32.41<108.66^{\circ}$ \\
\hline & \multicolumn{2}{|c|}{$\mathbf{I}_{\mathbf{1}} / \mathbf{k A}$} & \multicolumn{2}{|c|}{$\mathbf{I}_{2} / \mathbf{k A}$} & \multicolumn{2}{|c|}{ Fault current } \\
\hline & Pos.-Seq. comp. & Neg.-Seq. comp. & Pos.-Seq. comp. & Neg.-Seq. comp. & I & $\mathbf{k A}$ \\
\hline $\begin{array}{l}\text { Simulated } \\
\text { value }\end{array}$ & $3.65<-65.92^{\circ}$ & $3.46<111.45^{\circ}$ & $3.61<-65.61^{\circ}$ & $3.46<112.63^{\circ}$ & $6.14 \angle$ & $57.61^{\circ}$ \\
\hline $\begin{array}{c}\text { Calculated } \\
\text { value }\end{array}$ & $3.63 \angle-65.74^{\circ}$ & $3.45<112.42^{\circ}$ & $3.60<-65.42^{\circ}$ & $3.44 \angle 111.74^{\circ}$ & $6.14 \angle$ & $56.93^{\circ}$ \\
\hline
\end{tabular}

Table 1 shows on condition that 3-phase fault occurs at $f$, the maximum amplitude error between output results of the fault current calculation program and simulation results is $2.3 \%$, and the maximum error of the phase is $1.3^{\circ}$. Table 2 shows on condition that 2-phase fault occurs at $f$, the maximum amplitude error between output results of the fault current calculation program and simulation results is $4.1 \%$, and the maximum error of the phase is $2.4^{\circ}$. the error is permitted in relay protection setting, which is mainly caused during the processing of simulation results. Therefore, the simulation results show that the fault analysis method of the power grid with different types of wind turbines proposed in 
this paper is correct, and the fault analysis method can satisfy the fault characteristics analysis in grid and requirements of the application of relay protection principle.

\section{Conclusions}

To solve technical problems that existing the fault analysis method can't meet the fault current calculation of the power grid with different types of wind turbines, this paper according to the basic principle of fault current calculation method establishes fault current calculation models of different types of wind turbines. Then, combined with fault current calculation models of DWTG and DFIG, a novel fault analysis method of power grid with different types of wind turbines is proposed. Moreover, the accuracy of calculation results is verified by simulation. The result shows that the fault analysis method of power grid with different types of wind turbines proposed in this paper is correct. And it can meet the requirement of fault analysis and relay protection setting calculation of the power grid with different types of wind turbines.

\section{Acknowledgement}

This work was supported by the National Natural Science Foundation of China (Grant No. 51177058).

\section{References}

[1] Tsili M, Papathanassiou S. A review of grid code technical requirements for wind farms[J]. IET Renewable Power Generation, 2009, 3(3): 308-332.

[2] Han Aoyang, Zhang Zhe, Yin Xianggen, et al. Research on fault characteristic and grid connecting-point protection scheme for wind power generation with doubly-fed induction generator[J]. Transactions of China Electrotechnical Society, 2012, 27(4):233-239.

[3] Xiangping Kong, Zhe Zhang, XianggenYin. Study on Fault Current Characteristics and Fault Analysis Method of Power Grid With Inverter Interfaced Distributed Generation [J]. Proceedings of the CSEE, 2013, 33(34): 65-74.

[4] Zhengrong $\mathrm{Wu}$, Gang Wang, Haifeng Li, et al. Faut Characteristics Analysis of Distribution Networks Considering Control Scheme of Inverter Interfaced Distributed Generations [J]. Automation of Electric Power Systems. 2012, 36(18): 92-96,108.

[5] Pan Guoqing, Zeng Dehui, Wang Gang, et al. Fault Analysis on Distribution Network With Inverter Interfaced Distributed Generations Based on PQ Control Strategy [J]. Proceedings of the CSEE, 2014, 34(4): 555-561.

[6] Morren J, de Haan S W H. Ride through of wind turbines with doubly-fed induction generator during a voltage dip [J]. IEEE Transaction on Energy Conversion, 2005, 20(1): 435-441.

[7] Zheng Tao, Wei Zhanpeng, Chi Yongning, et al. Short-circuit Current Characteristic of Doubly Fed Induction Generator Considering Crowbar Protecion Insertion Time. Automation of Electric Power Systems, 2014, 38(5): 25-30.

[8] Xiangping Kong, Zhe Zhang, XianggenYin. Study on Fault Current Characteristics of DFIG Considering Impact of Crowbar Protection [J]. Transactions of China Electrotechnical Society, 2015, 42(6): 45-50.

[9] Xiangping Kong, Zhe Zhang, Xianggen Yin. Study of fault current characteristics of DFIG considering dynamic response of RSC. IEEE Transactions on Energy Conversion, 2014,26(2):278-287.

[10] Ouyang Jinxin, Xiong Xiaofu. Research on Short circuit Current of Doubly-fed Induction Generators Under Rotor Excitation Control[J]. Proceedings of the CSEE. 2014, 34(34): 6083-6092. 
[11] Xiao Fan, Zhang Zhe, Yin Xianggen, et al. Fault Analysis of Power System Considering Doubly-fed Induction Generators at Uninterrupted Condition [J]. Transactions of China Electrotechnical Society,2015,30(17):77-84.

[12] Yang Zengli, Shi Dongyuan, Yang Xiongping, et al. A Study on the Universality of the Protection Setting Calculation Software[J]. Automation of Electric Power Systems, 2007, 31(14): 89-93.

[13] Feng Liqiao, Yuan Chongguang, Xu Wenyu. Development of a Practical Multi-function Software for Short Circuit Calculation [J]. Power System Technology, 1999, 23(4): 45-48.

[14] Amirnaser Yazdani, Reza Iravana. A Unified Dynamic Model and Control for the Voltage-Sourced Converter Under Unbalanced Grid Conditions [J]. IEEE Transactions on Power Delivery, 2006,21(3):1620-1629.

[15] State Grid. GB/T 19963-2011 Technical rule for connecting wind farm to power system[S]. 2011. 